\title{
PATTERNS OF 50 ETF OPTIONS IMPLIED VOLATILITY IN CHINA: ON IMPLIED VOLATILITY FUNCTIONS
}

\section{Pengshi Li', Yan Lin', Yuting Zhong ${ }^{3}$}

\footnotetext{
1 Dong Guan University of Technology, School of Economics and Management, Department of Accounting and Finance, China, 2018074@dgut.edu.cn;

2 Peking University, HSBC Business School, Sargent Institute of Quantitative Economics and Finance, China, linyantony@pku.edu.cn;

3 School of Guangdong Provincial Committee of CPC, Institute of Socialism with Chinese Characteristics, Department of Political Economy, China, 729163092@qq.com.
}

\begin{abstract}
The aim of this study is to examine the volatility smile based on the European options on Shanghai stock exchange 50 ETF. The data gives evidence of the existence of a well-known $U$-shaped implied volatility smile for the SSE 50 ETF options market in China. For those near-month options, the implied volatility smirk is also observed. And the implied volatility remains high for the short maturity and decreases as the maturity increases. The patterns of the implied volatility of SSE 50 ETF options indicate that in-the-money options and out-of-the-money options are more expensive relative to at-the-money options. This makes the use of at-the-money implied volatility for pricing out-of- or in-the-money options questionable. In order to investigate the implied volatility, the regression-based implied volatility functions model is considered employed to study the implied volatility in this study as this method is simple and easy to apply in practice. Several classical implied volatility functions are investigated in this paper to find whether some kind of implied volatility functions could lead to more accurate options pricing values. The potential determinants of implied volatility are the degree of moneyness and days left to expiration. The empirical work has been expressed by means of simple ordinary least squares framework. As the study shows, when valuing options, the results of using volatility functions are mixed. For far-month options, using atthe-money implied volatility performs better than other volatility functions in option valuation. For near-month options, the use of volatility functions can improve the valuation accuracy for deep in-the-money options or deep out-of-the-money options. However, no particular implied volatility function performs very well for options of all moneyness level and time to maturity.
\end{abstract}

Keywords: Implied volatility, smile patterns, implied volatility functions.

JEL Classification: G10, G13.

APA Style Citation: Li, P.-S., Lin, Y., \& Zhong, Y.-T. (2020). Patterns of 50 ETF Options Implied Volatility in China: On Implied Volatility Functions. E\&M Economics and Management, 24(1), 135-145. https://doi.org/10.15240/tul/001/2021-1-009

\section{Introduction}

The implied volatilities are prospective estimates which reflect future expectations about underlying asset volatility. The implied volatility can be seen as the market participants' assessment of the uncertainty of the underlying asset. Implied volatilities are obtained by matching a set of market option prices with given strike price and time to maturity to those produced by Black-Scholes-Merton model (BSM model) using the same strike price and time to maturity. When the implied volatilities are plotted against various strike prices or different moneyness, one can obtain the implied volatility smile curve, while the pattern of implied volatilities across time to expiration is usually referred to as the term structure of implied volatilities. The smile-shaped pattern of 
implied volatility has provided evidence against the constant volatility assumption inherent in the BSM model. The volatility smile observed in the options market indicates that deep out-ofthe-money and deep in-the-money options are priced higher than the price obtained by the BSM model. The persistence of the implied volatility smile is common in the currency options market and stock market. One explanation for the smile in foreign currency options market is that the volatility of an exchange rate is not constant and frequently exhibit jumps. One explanation for the smile in equity options concerns leverage effect.

The shape of the volatility smile, and its dependence on moneyness and time to expiration, has motivated researchers to model implied volatility as a quadratic function of moneyness and time to maturity. MacBeth and Mervile (1979), Rubinstein (1985, 1994), Derman and Kani (1994) have studied the relationship between implied volatility and moneyness. They found that the stylized patterns of implied volatility are varying for different time-to-expiration and degree of moneyness. Some earlier studies such as Dumas et al. (1998), Peña et al. (1999) applied various regression models to assess the smile effects on the options market and the implied volatility functions are used to determine how implied volatility is attributable to time-toexpiration and moneyness. Dumas et al. (1998) use the deterministic volatility function (DVF) approach to modeling implied volatility. DVF modeling is useful because it provides estimates of volatility for a combination of moneyness and maturity that is not available in observed options prices. They find that a relatively parsimonious function works well for describing the observed implied volatility structure. Using puts and calls data on the Spanish IBEX-35 index, Peña et al. (1999) employ simple regression and Granger causality tests to analyze the pattern of implied volatilities across exercise prices. Moreover, Peña et al. (2001), Engström (2002), Andreou et al. (2014), Tanha and Dempsey (2015), Narain et al. (2016) study the implied volatility smile for individual stocks as well as for index options and analyze the determinants of IV through regression based models. Peña et al. (2001) study the effect of bid-ask spread on the smile by fitting several implied volatility functions. Engström (2002) found the smile patterns for Swedish equity options. Using at-the-money implied volatilities as benchmark, Engström (2002) found that although the benchmark model performs best for at-the-money options, the use of volatility function could improve the valuation accuracy for deep in-the-money options. Andreou et al. (2014) examines several alternative symmetric and asymmetric model specification of regression-based deterministic volatility model to identify the one that best characterize the implied volatility functions of S\&P 500 Index options in the period 1996-2009. Using multivariate analysis and employing an impulse response function, Tanha and Dempsey (2015) investigate the structural relationships and dynamics of the volatility smile in relationship to the option liquidity, key features of the underlying asset and market momentum. Narain et al. (2016) suggest that there are asymmetric volatility of Nifty index options across time and strike price and Nifty futures' volumes and momentum are found to be significant determinants of implied volatility. Bhat (2019) identifies historical volatility, momentum and jumps in the exchange rate, time to maturity, traded volume of options and volatility in the stock market appear to Grangercause the shape of the implied volatility smile. Soini and Lorentzen (2019) studies the determinants of crude oil option through regression analysis. Their research suggests implied volatility as a function of moneyness is positively and significantly correlated basis and transaction costs. Implied volatility smile is valuable to options traders and portfolio managers. The study of implied volatility function identifies the determinants of the implied volatility and provides the information of how in or out of money options are priced in the market.

This study aims to deal with the stylized patterns in implied volatility for 50 ETF options in China, and to analyze effect of different implied volatility functions in options valuation. At first, an attempt has been made to examine the actual shape of the implied volatility smile. The main findings show that in 50 ETF options market, deep out-of-the-money and deep-in-the-money options have higher implied volatilities than at-the-money options. The smile in the equity options market in China indicates the mispricing of options, hence, several types of implied volatility functions are analyzed the effect in the improvement of valuation accuracy. The study has been organized as the following: the methodology is discussed 
in Section 2; whereas the 50 ETF options and data source are presented in Section 3; Section 4 discusses the empirical results; Section 5 ends with the conclusion.

\section{Methodology}

The implied volatility is extracted by using the BSM model. This must be done numerically because the BSM formula cannot be solved for the implied volatility in terms of the other parameters. In this study, the settle prices for the options and the underlying assets are used as inputs to retrieve the implied volatility from the BSM model.

The implied volatility of each option is obtained for each day during the estimation period via the Bisection method. Two initial implied volatility values $\sigma_{i v}^{L}$ and $\sigma_{i v}^{H}$ are needed before proceeding the Bisection method. Each implied volatility corresponding to an option value $c_{L}$ and $c_{H}$. Given the option market price $c_{m}$, an estimation is calculated through the following linear interpolation:

$$
\sigma_{\text {new }}=\sigma_{i v}^{L}+\left(c_{m}-c_{L}\right) \frac{\sigma_{i v}^{H}-\sigma_{i v}^{L}}{c_{H}-c_{L}}
$$

If the option price at $\sigma_{\text {new }}$ is less than $c_{m}$, the lower volatility $\sigma_{i v}^{L}$ is replaced with $\sigma_{\text {new }}$, if the option price at $\sigma_{\text {new }}$ is larger than $C_{m}$, the higher volatility $\sigma_{i v}^{H}$ is replaced with $\sigma_{n e w}$. The procedure is carried on until the option price at $\sigma_{\text {new }}$ and $c_{m}$ is close enough for the given degree of accuracy.

Different deterministic volatility functions are chosen to run multiple regression under ordinary least squares on implied volatility over the estimation period. The specifications of model employed are mainly based on previous studies like Engström (2002), Rouah and Vainberg (2012).

Model 1:

$$
\begin{aligned}
& \sigma_{i v=} \sigma_{\text {ATM }} \\
& \text { Model 2: } \\
& \sigma_{i v}=\alpha+\beta_{1} \ln (M)+\beta_{2} \ln (M)^{2}+\varepsilon_{2} \\
& \text { Model 3: } \\
& \sigma_{i v}=\alpha+\beta_{1} \ln (M)+\beta_{2} \ln (M)^{2}+\beta_{3}(T-t)+ \\
& +\beta_{4}(T-t)^{2}+\beta_{5} \ln (M)(T-t)+\varepsilon_{3} \\
& \text { Model 4: } \\
& \sigma_{i v}=\alpha+\beta_{1} U+\beta_{2} D^{2}+\varepsilon_{4} \\
& \text { Model 5: } \\
& \sigma_{i v}=\alpha+\beta_{1} U+\beta_{2} D^{2}+\beta_{3}(T-t)+ \\
& +\beta_{4}(T-t)^{2}+\varepsilon_{5}
\end{aligned}
$$

Model 6:

$$
\begin{aligned}
& \sigma_{i v}=\alpha+\beta_{1} \frac{\ln (M)}{\sigma_{A T M} \sqrt{T-t}}+ \\
& +\beta_{2}\left(\frac{\ln (M)}{\sigma_{A T M} \sqrt{T-t}}\right)^{2}+\varepsilon_{6}
\end{aligned}
$$

In the following specifications $\sigma_{i v}$ stands for Black-Scholes implied volatility, $\sigma_{A T M}$ stands for implied volatility of at-the-money options, $M$ stands for the moneyness, and $(T-t)$ for the time left to expiration, where $\alpha, \beta$ 's and $\varepsilon_{i}$, $i=2, \ldots 6$ are model intercepts terms, regression coefficients and error terms respectively. In model 4 and $5, U$ and $D$ are defined as:

$$
\begin{aligned}
& U=\ln (M) \text { if } \ln (M)<0, \text { and } U=0 \text { if } \ln (M) \geq 0 . \\
& D=\ln (M) \text { if } \ln (M) \geq 0 \text {, and } D=0 \text { if } \ln (M)<0 .
\end{aligned}
$$

Model 1 assumes constant volatility with no dependence on the time to expiration of moneyness. In this model the implied volatility of options closest to at-the-money is chosen to be the benchmark. Model 2 assumes implied volatility to be a quadratic function of options' moneyness, with no dependence on maturity. By taking a linear and quadratic moneyness terms, model 2 takes into the account of curvature of implied volatility curve across different moneyness. Model 3 adds a dependence on time to expiration, this specification allows for the relationship between implied volatility and time to expiration term to be linear and quadratic, and with an interaction between moneyness and time to expiration contained in its last term. Model 3 is able to capture the time effects on the smiling, Tab. 1 and Fig. 2-3 clearly indicate the shape of the implied volatility depends on days left to expiration. Engström (2002) suggested, that the squared time to expiration terms in this specification could be seen as a measure of the kurtosis in the underlying asset return distribution. Model 4 recognizes the potential asymmetric in the shape of the volatility function, this pattern is shown in Fig. 2-3 and in several previous studies. In particular, Model 4 assumes that the left side of the volatility function is linear on the moneyness, and the right side of the volatility function gets some degree of curvature as the moneyness increases. In model 5 the linear and quadratic terms of time to expiration are also included. In 
model 6 a quadratic function of standardized moneyness is employed.

The out of sample fit of the different volatility is tested in the one-month evaluation period. For the appropriate parameter values, the volatility to use for each option can be obtained by the fitted value of the volatility functions. Using the fitted implied volatility, BSM model options price is then calculated for each day. The BSM model price given each volatility function is compared with the market option price. The data is fitted to different models to find a suitable implied volatility function.

\section{Data Analysis}

According to the information from the website of Shanghai Stock Exchange and Hilliard and Zhang (2019) Shanghai Stock Exchange (SSE) began trading options on February 9, 2015. The underlying of the SSE 50 ETF options is 50 Exchange Traded Open-End Index Securities Investment Fund (50ETF). 50 ETF options contracts are standardized as uniform contract prepared by SSE, which states that buyers reserve the right to buy or sell such underlying assets as the agreed shares at a certain price and a certain time in the future. The options traded are European type and can be Call or Put types. Contracts are physically settled and each contract represents the right to buy or sell 10,000 SSE 50 ETF. The options' settle price each day is determined by the average executed price in the closing call auction. The SSE 50 ETF options have four types of expiration months: the current month, next month, and the first month of the following two consecutive quarters. The expiration date is the fourth Wednesday of each expiration month. The exercise date is the same as the expiration date and the delivery date is the day after exercise date. At initiation, there will be nine strike prices (1 at-the-money, 4 out-ofthe money and 4 in-the-money). The trading hours are 9:15-9:25, 9:30-11:30 in the morning and 13:00-15:00 in the afternoon. The period between 9:15-9:25 is for opening call auction and $14: 57-15: 00$ is for closing call auction.

The daily data set provided by Wind Info, Inc. are used in this study. The daily data used consists of call and put options during the sample period February 9, 2015, to April 28, 2016. The data consists of the date of the introduction of options, the expiration dates, the strike prices, options prices (settle prices), options types, SSE 50 ETF prices, and its trading volume. As shown in Tab. 1 , ETF prices ranges from $¥ 1.886$ to $¥ 3.427$ with mean $¥ 2.480$. The average trading volume of ETF is $1,087.65$ million shares per day. At the outset, the dataset consists of 18,715 call options and 18,725 put options. During the sample period the average call price on one underlying asset was $¥ 0.212$, the average put price is $¥ 0.27$. The maximum call price is $¥ 1.236$, the maximum put price is $¥ 1.79$, the minimum options price is $¥ 0.0001$. The maximum days to expiration are 244 days. The maximum strike price and the minimum strike price is $¥ 1.8$ and $¥ 3.6$ respectively. The theoretical options prices

\section{Tab. 1: Summary statistics}

\begin{tabular}{l|c|c|c|c|c|c} 
& $\mathbf{N}$ & Min & Max & Mean & Median & Std. dev. \\
\hline ETF price & 260 & 1.886 & 3.427 & 2.480 & 2.394 & 0.385 \\
\hline ETF volume (million shares) & 260 & 89.17 & $9,146.83$ & $1,087.65$ & 633.23 & $1,267.23$ \\
\hline & & & & & & \\
\hline Call price & 18,715 & 0.0001 & 1.236 & 0.212 & 0.147 & 0.218 \\
\hline Days to expiration & 18,715 & 1.00 & 244 & 83.58 & 64.00 & 65.08 \\
\hline Strike price & 18,715 & 1.80 & 3.60 & 2.53 & 2.50 & 0.43 \\
\hline & & & & & & \\
\hline Put price & 18,728 & 0.0001 & 1.790 & 0.270 & 0.180 & 0.280 \\
\hline Days to expiration & 18,728 & 1.00 & 244 & 83.53 & 64.00 & 65.09 \\
\hline Strike price & 18,728 & 1.80 & 3.60 & 2.53 & 2.50 & 0.43 \\
\hline
\end{tabular}


are calculated by BSM model, in which the riskfree rate is Shanghai Inter Bank Offered Rate (SHIBOR).

In this study, the sample period is divided into an estimation period: February 9, 2015 to February 29, 2016, and an evaluation period: March 1, 2016 to April 28, 2016. The following procedure is employed for data cleaning: Firstly, only date for which non-zero quotes for both call and put options exist are included in the sample; Secondly, options with less than 7 days left to expiration are excluded. Finally, observations that do not satisfy the upper and lower bounds for European options (2) and (3) are omitted.

$$
\begin{aligned}
& \max \left(S_{0}-K e^{-r T}, 0\right) \leq c \leq S_{0} \\
& \max \left(K e^{-r T}, 0\right) \leq p \leq K e^{-r T}
\end{aligned}
$$

In the bounds above, $S_{0}$ denotes the underlying asset price, $K$ is the strike price; $c$ and $p$ are value of the European call and put options; $T$ denotes time to expiration of options and $r$ is the risk-free rate. In total, the estimation sample period consists of 21,689 contracts whereas the evaluation sample consists of 2,543 contracts.

Next the summary of the descriptive statistics of the implied volatility is presented. All options are divided in to five subgroups according to the options' time to expiration and six subgroups according to the options' moneyness. An option's time to expiration is defined as the days left to the option's maturity.
The five subgroups are divided according to the following days left to expiration: $7-30$ days; 31-90 days; 91-150 days; 151-210 days; $211-244$ days. Moneyness is defined as the ratio of the strike price to the underlying asset's closing price for put options. For call options, moneyness is defined as the ratio of the underlying asset's closing price to strike price. An option is defined to be deep out-themoney when its moneyness is less than or equal to 0.9 and deep in-the-money when its moneyness is larger than 1.2. An at-the-money option is defined as its moneyness is between 0.98 and 1.02. The moneyness groups are divided unevenly with one additional subgroup for deep in-the-money options. The moneyness intervals are given by the following degrees of moneyness: less or equal to $0.9 ; 0.9-0.98$; $0.98-1.02$; 1.02-1.2; larger than 1.2.

In Tab. 2, we compute the average of the implied volatility over the alternative time to expiration/moneyness subgroups described above. It is seen clearly that the implied volatility for in-the-money options and outof-the money options are higher than at-themoney options in all time to expiration intervals except for the 31-90 days interval. Tab. 2 clearly show that Shanghai 50 ETF options are smiling, but the implied volatility curve varies according to time-to-expiration. Fig. 1 presents the implied volatility curve for one-month, twomonth and far month options. It is seen clearly that Shanghai 50 ETF options implied volatility differs between maturity subgroups. For options in the full sample, in most of the time as the

\section{Tab. 2: Average implied volatility with respect to time to expiration and moneyness}

\begin{tabular}{l|c|c|c|c|c|c}
\multirow{2}{*}{ Moneyness } & \multicolumn{7}{c}{ Time (days left) to expiration } \\
\cline { 2 - 7 } & $\mathbf{7 - 3 0}$ & $\mathbf{3 1 - 9 0}$ & $\mathbf{9 1 - 1 5 0}$ & $\mathbf{1 5 1 - 2 1 0}$ & $\mathbf{2 1 1 - 2 4 4}$ & Total \\
\hline \multicolumn{2}{|c|}{ Average implied volatility for all options in the sample period } \\
\hline$<0.90$ & $47.42 \%$ & $36.94 \%$ & $34.62 \%$ & $34.38 \%$ & $35.94 \%$ & $37.84 \%$ \\
\hline $0.90-0.98$ & $33.07 \%$ & $29.86 \%$ & $29.92 \%$ & $29.28 \%$ & $32.34 \%$ & $30.55 \%$ \\
\hline $0.98-1.02$ & $30.73 \%$ & $30.23 \%$ & $29.48 \%$ & $27.88 \%$ & $30.06 \%$ & $29.85 \%$ \\
\hline $1.02-1.10$ & $38.22 \%$ & $36.29 \%$ & $37.06 \%$ & $35.89 \%$ & $36.15 \%$ & $36.60 \%$ \\
\hline $1.10-1.20$ & $55.87 \%$ & $46.23 \%$ & $42.63 \%$ & $39.50 \%$ & $39.01 \%$ & $45.08 \%$ \\
\hline$>1.20$ & $90.56 \%$ & $62.08 \%$ & $57.08 \%$ & $49.20 \%$ & $52.54 \%$ & $62.50 \%$ \\
\hline Total & $45.47 \%$ & $39.08 \%$ & $38.30 \%$ & $35.35 \%$ & $35.10 \%$ & $38.95 \%$ \\
\hline
\end{tabular}




\section{Fig. 1: Implied volatility with respect to time to expiration}

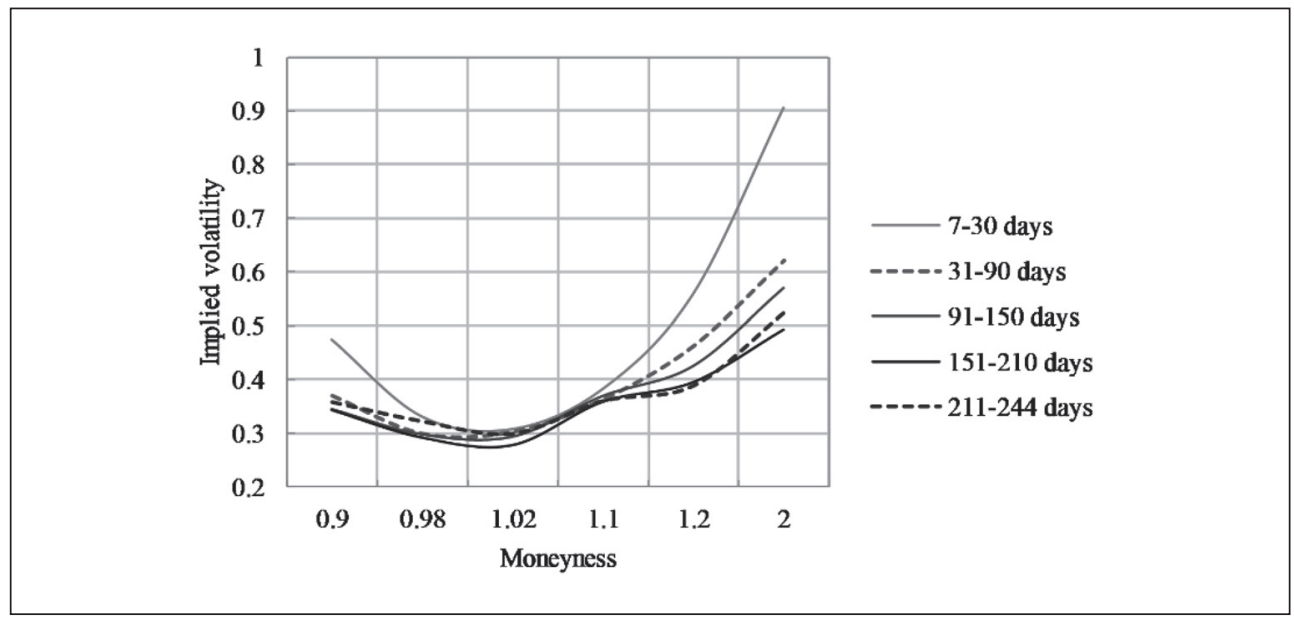

Source: own

\section{Fig. 2:} Implied volatility for calls and puts $7-30$ days left to expiration

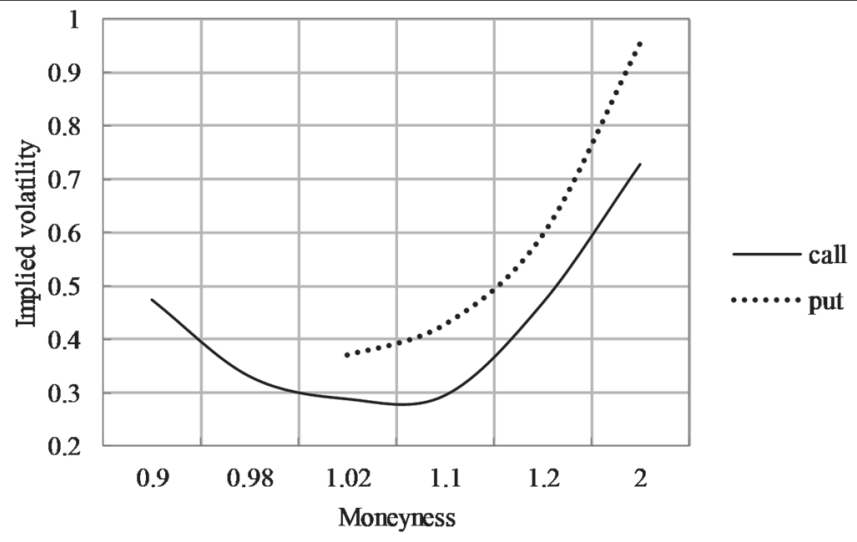

days left to expiration increases, the implied volatility tends to decrease in each moneyness subgroups. Moreover, it can be discerned from Fig. 1 that the implied volatility curve exhibits more U-shaped in the near-month options. If the smile curve for 7-30 days interval and 151-210 days or 211-244 days left to expiration are compared, the smile for the 7-30 days group is more pronounced than others. And the pattern of "dying smiling" can also be discerned as the smile fades away as time to expiration approaches the longer term.

Fig. 2 presents the implied volatility when the smile is obtained from call and put options independently respect to 7-30 days left to expiration. It clearly shows that for the nearmonth options, the implied volatility for puts is larger than calls for different moneyness. The 


\section{Fig. 3: Implied volatility for calls and puts 91-150 days left to expiration}

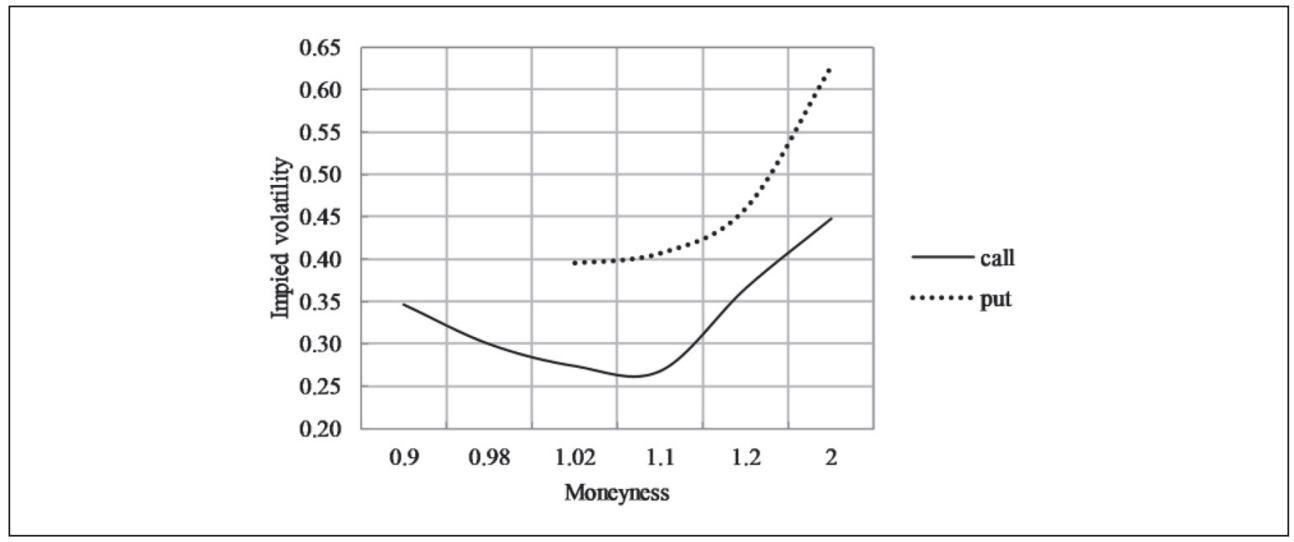

Source: own

\section{Fig. 4: Implied volatility for calls and puts 211-244 days left to expiration}

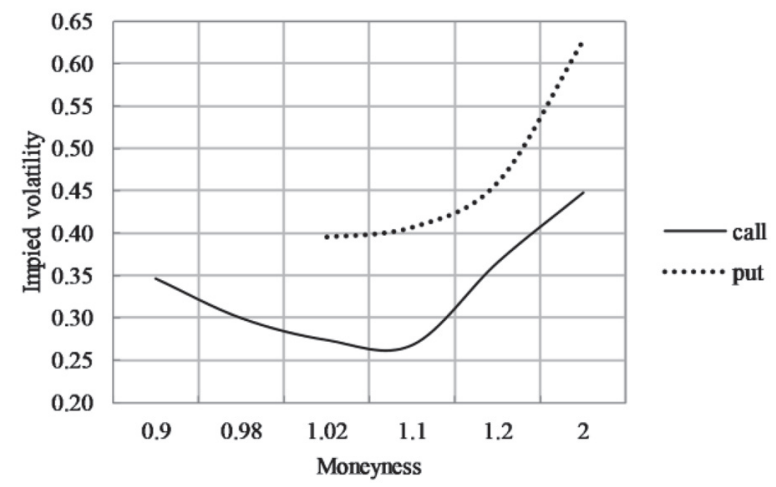

near-month puts exhibit the phenomena of "volatility smirk" or "volatility sneer", and the nearmonth calls show the typical "volatility smile". Fig. 3 and 4 present the implied volatility for farmonth call and put options. As the days left to expiration increase, the U-shaped the implied volatility became less pronounced especially for call options. According to the results of Tab. 1 and Fig. 1-4, the time to expiration and moneyness are two important factors which determine the shape of the smiling.

\section{Results and Discussions}

The results of fitting the relative implied volatilities to the different models are presented in Tab. 3. In terms of the multiple $R$ criteria, the results suggest that Model 3 is the best model at capturing variation in implied volatility attributable to moneyness, time to expiration and the cross effect from both of the variables. The implied volatility pattern in Model 3 explains around $70 \%$ of the variation in the implied volatility. The second best specification 


\section{Tab. 3: Coefficients for different specifications of the volatility functions}

\begin{tabular}{l|c|c|c|c|c}
\multirow{2}{*}{ Variables } & \multicolumn{5}{|c}{ Alternative specification of the volatility function parameters } \\
\cline { 2 - 6 } & Model 2 & Model 3 & Model 4 & Model 5 & Model 6 \\
\hline Constant $\alpha$ & 0.362582 & 0.489397 & 0.365718 & 0.498445 & 0.390103 \\
\hline $\ln (M)$ & 0.444757 & 0.716623 & & & \\
\hline $\ln (M)^{2}$ & 2.37177 & 2.360037 & & & \\
\hline$(T-t)$ & & -0.95862 & & -0.98241 & \\
\hline$(T-t)^{2}$ & & 1.221094 & & 1.215564 & \\
\hline $\ln (M)(T-t)$ & & -1.18855 & & & \\
\hline$U$ & & & -0.26945 & -0.25379 & \\
\hline$D^{2}$ & & & 3.768153 & 3.764904 & \\
\hline$\left(\ln (M) / \sigma_{\text {ATM }} \sqrt{T-t}\right)$ & & & & & 0.065884 \\
\hline$\left(\ln (M) / \sigma_{\text {ATM }} \sqrt{T-t}\right)^{2}$ & & & & & 0.021926 \\
\hline $\operatorname{Multiple} R$ & & & & & \\
\hline
\end{tabular}

Source: own

\section{Tab. 4: Forecast error for different volatility functions}

\begin{tabular}{|c|c|c|c|c|c|}
\hline Model 1 & Model 2 & Model 3 & Model 4 & Model 5 & Model 6 \\
\hline \multicolumn{6}{|c|}{ Panel A: RMSE for different specifications } \\
\hline 0.021177 & 0.047511 & 0.040407 & 0.048507 & 0.041473 & 0.053796 \\
\hline \multicolumn{6}{|c|}{ Panel B: MAPE for different specifications } \\
\hline 0.175568 & 0.519332 & 0.523552 & 0.710053 & 0.829724 & 0.738927 \\
\hline
\end{tabular}

is Model 5, which explains about $67 \%$ of the variation in the volatility.

Next, out-of-sample test is carried out for each model. In Tab. 4, two commonly measures RMSE and MAPE of the goodness of fit are used to determine the accuracy of the out-ofsample performance for each volatility function. RMSE and MAPE is defined as:

$$
\begin{aligned}
& R M S E=\sqrt{\frac{1}{n} \sum_{i=1}^{n}\left|y_{i}-\hat{y}_{i}\right|}=\sqrt{\frac{1}{n} \sum_{i=1}^{n}\left|e_{i}\right|} \\
& M A P E=\frac{1}{n} \sum_{i=1}^{n}\left|\frac{y_{i}-\hat{y}_{i}}{y_{i}}\right|=\frac{1}{n} \sum_{i=1}^{n}\left|\frac{e_{i}}{y_{i}}\right|
\end{aligned}
$$

where $y_{i}$ represents the market price, $\hat{y}_{i}$ represents the forecast value and $e_{i}=y_{i}-\hat{y}_{i}$ is the error. In Panel A, the root mean squared error (RMSE) between the model forecast values and the closing market prices are presented. Model 1 produces smaller RMSE than other models. According to the RMSE criteria Model 1 is clearly the best model. Model 3 is the second best model in terms of RMSE, which implies that the inclusion of linear and quadratic terms of moneyness and time to maturity can increase the forecast performance. In Panel $B$, mean absolute percentage error (MAPE) is presented. According to this criteria, Model 1 is the best specification. However, Model 2 and 3 is very close, the MAPE of Model 3 is just slightly higher (about 0.004) than Model 2. 


\section{Tab. 5: RMSE between market price and forecast value displayed with respect
to maturity and moneyness}

\begin{tabular}{|c|c|c|c|c|c|c|c|}
\hline Maturity & Moneyness & Model 1 & Model 2 & Model 3 & Model 4 & Model 5 & Model 6 \\
\hline \multirow{6}{*}{$7-30$} & $<0.90$ & 0.000687 & 0.000638 & 0.001846 & 0.001873 & 0.004879 & 0.001493 \\
\hline & $0.90-0.98$ & 0.004065 & 0.014012 & 0.023701 & 0.018504 & 0.030876 & 0.01519 \\
\hline & $0.98-1.02$ & 0.007996 & 0.020434 & 0.033959 & 0.020977 & 0.035236 & 0.025421 \\
\hline & $1.02-1.10$ & 0.009476 & 0.019891 & 0.031355 & 0.018335 & 0.02847 & 0.028016 \\
\hline & $1.10-1.20$ & 0.017084 & 0.0159 & 0.015931 & 0.016385 & 0.015177 & 0.019886 \\
\hline & $>1.20$ & 0.027098 & 0.023937 & 0.019384 & 0.024323 & 0.021751 & 0.016733 \\
\hline \multirow{6}{*}{$31-90$} & $<0.90$ & 0.00619 & 0.017221 & 0.012835 & 0.031691 & 0.027361 & 0.01529 \\
\hline & $0.90-0.98$ & 0.00859 & 0.030974 & 0.031168 & 0.041548 & 0.042588 & 0.036187 \\
\hline & $0.98-1.02$ & 0.014342 & 0.036784 & 0.039344 & 0.037867 & 0.040939 & 0.045085 \\
\hline & $1.02-1.10$ & 0.01992 & 0.039788 & 0.042278 & 0.035716 & 0.037815 & 0.048976 \\
\hline & $1.10-1.20$ & 0.014493 & 0.038334 & 0.03603 & 0.030204 & 0.02752 & 0.039136 \\
\hline & $>1.20$ & 0.012143 & 0.0322 & 0.029629 & 0.023867 & 0.020227 & 0.016961 \\
\hline \multirow{6}{*}{$91-150$} & $<0.90$ & 0.031531 & 0.04131 & 0.037741 & 0.048053 & 0.042548 & 0.047899 \\
\hline & $0.90-0.98$ & 0.011632 & 0.045826 & 0.028289 & 0.061137 & 0.040584 & 0.054388 \\
\hline & $0.98-1.02$ & 0.019971 & 0.05784 & 0.045152 & 0.059581 & 0.046445 & 0.067301 \\
\hline & $1.02-1.10$ & 0.025544 & 0.055928 & 0.052291 & 0.053946 & 0.052719 & 0.061676 \\
\hline & $1.10-1.20$ & 0.041148 & 0.032491 & 0.042512 & 0.035954 & 0.047831 & 0.038607 \\
\hline & $>1.20$ & 0.066077 & 0.02157 & 0.036479 & 0.026183 & 0.039906 & 0.045546 \\
\hline \multirow{6}{*}{$151-210$} & $<0.90$ & - & - & - & - & - & - \\
\hline & $0.90-0.98$ & 0.014685 & 0.075853 & 0.057261 & 0.093446 & 0.061773 & 0.090081 \\
\hline & $0.98-1.02$ & 0.021171 & 0.088991 & 0.066669 & 0.091334 & 0.065106 & 0.103942 \\
\hline & $1.02-1.10$ & 0.037043 & 0.090359 & 0.065314 & 0.08311 & 0.063522 & 0.099838 \\
\hline & $1.10-1.20$ & 0.017674 & 0.125157 & 0.082358 & 0.110286 & 0.082446 & 0.128853 \\
\hline & $>1.20$ & - & - & - & - & - & - \\
\hline \multirow{6}{*}{$121-244$} & $<0.90$ & - & - & - & - & - & - \\
\hline & $0.90-0.98$ & 0.004082 & 0.081142 & 0.085101 & 0.103578 & 0.085715 & 0.095059 \\
\hline & $0.98-1.02$ & 0.016993 & 0.103515 & 0.0925 & 0.10666 & 0.089624 & 0.119469 \\
\hline & $1.02-1.10$ & 0.02659 & 0.096896 & 0.084445 & 0.091034 & 0.08408 & 0.103725 \\
\hline & $1.10-1.20$ & - & - & - & - & - & - \\
\hline & $>1.20$ & - & - & - & - & - & - \\
\hline Overall & & 0.021177 & 0.047511 & 0.040407 & 0.048507 & 0.041473 & 0.053796 \\
\hline
\end{tabular}

Source: own

In order to investigate whether the performance of each volatility function depends on the time to maturity and the moneyness, RMSE for each of the time to expiration/ moneyness subgroups and model is displayed in Tab. 5. As expected, Model 1 performs very well for at-the-money options. For the far-month (151-210 days/211-244 days left to expiration) options contracts, Model 1 outperforms Model 2-6. For the near-month (7-30 days left to 
expiration) options contracts, Model 1 still perform well for those at-the-money or near atthe-money options. However, for the near-month options contracts which are in-the-money or out-of-the money, Model 2 (for moneyness less than 0.9) and Model 5 (for moneyness between 1.1 and 1.2) perform better. Moreover, Model 6 outperforms other volatility function models for those deep in-the-money near-month options.

\section{Conclusions}

This study investigates the patterns of implied volatility for 50 ETF option in China. The smile and skew patterns of implied volatility are observed in the market. Therefore, the at-themoney implied volatility is not appropriate to value options that are deep in-the-money or out-of-the-money. Using at-the-money implied volatility as a benchmark, the empirical work has been expressed in ordinary least square method and the relative performance of different model is evaluated. The volatility estimates according to each volatility function are used to price options in the evaluation period.

In summary, when valuing options, the results of using volatility functions rather than at-the-money implied volatility are mixed, and it is hard to say whether the use of implied volatility functions lead to the improvement in option pricing accuracy. For short maturity in or out-of-the money options, the quadratic function of moneyness and the function considering the asymmetric and time effect are better choice. For long maturity options, at-the-money implied volatility perform better in option valuation compared to other volatility functions. For short maturity deep in-the-money options, the best performance overall for in or out-of-the money is achieved by using a quadratic function of the options' standardized moneyness. Besides time to maturity and moneyness, other determinant such as liquidity cost is also important to the explanation of implied volatility smile (Peña et al., 1999, 2001). Usually, the liquidity cost is proxied by bid-ask spread, however the daily bid and ask price of 50 ETF option is not available. In the following study, we will try to incorporate the liquidity cost and other determinants into the volatility function model to better understand the determinants and patterns of the 50 ETF options implied volatility.

Acknowledgement: This work is supported by Blockchain and Technology Finance Team
Project of Guangdong (2019WCXTD007); Dongguan University of Technology Major Program Key Laboratory of Technology Finance (KCYXM2019001); Guangdong Provincial Humanities and Social Science Platform - Pearl River Delta Industrial Ecology Research Center (2016WZJD005); Guangdong Social Science Research Base Quality and Brand Development and Research Center of Dongguan University of Technology (GB200101).

\section{References}

Andreou, P. C., Charalamous, C., \& Martzoukous, S. H. (2015). Assessing the performance of symmetric and asymmetric implied volatility functions. Review of Quantitative Finance and Accounting, 42(3), 373-397. https://doi.org/10.1007/S11156-0130346-z

Bhat, A. P. (2018). The economic determinants of the implied volatility function for currency options: Evidence from India. International Journal of Emerging Market, 13(6), 1798-1819. https://doi.org/10.1108/ IJoEM-08-2017-0308

Derman, E., \& Kani, I. (1994). Riding on a smile. Risk, 7(02), 32-39. Retrieved from https://www.researchgate.net/publication/ 239059413

Dumas, B., Fleming, J., \& Whaley, R. E. (1998). Implied volatility functions: Empirical tests. The Journal of Finance, 53(6), 20592106. https://doi.org/10.1111/0022-1082.00083

Engström, M. (2002). Do Swedes smile? On implied volatility functions. Journal of Multinational Financial Management, 12(4-5), 285-304. https://doi.org/10.1016/s1042$444 \times(02) 00012-9$

Hilliard, J., \& Zhang, H. (2019). Regulatory Soft Interventions in the Chinese Market: Compliance Effects and Impact on Option Market Efficiency. The Financial Review, 54(2), 265-301. https://doi.org/10.1111/fire.12189

Hull, J. (2012). Options, futures and other derivatives. London: Pearson.

MacBeth, J. D., \& Merville, L. J. (1979). An empirical examination of the BlackScholes call option pricing model. The Journal of Finance, 34(5), 1173-1186. https://doi. org/10.2307/2327242

Narain, Nigam, N. K., \& Pandey, P. (2016). Behavior and determinants of implied volatility in Indian market. Journal of Advance in 
Management Research, 13(3), 271-291. https://doi.org/10.1108/JAMR-09-2015-0062

Peña, I., Rubio, G., \& Serna, G. (1999). Why do we smile? On the determinants of the implied volatility function. Journal of Banking \& Finance, 23(8), 1151-1179. https://doi. org/10.1016/s0378-4266(98)00134-4

Peña, I., Rubio, G., \& Serna, G. (2001). Smiles, Bid-ask Spreads and Option Pricing. European Financial Management, 7(3), 351-374. https://doi.org/10.1111/1468-036X.00160

Rosenberg, J. (2000). Implied Volatility Functions: A Reprise. The Journal of Derivatives, 7(3), 51-64. https://doi. org/10.3905/jod.2000.319124

Rouah, F. D., \& Vainberg, G. (2012). Option Pricing Models and Volatility Using Excel-VBA. New Jersey, NJ: John Wiley \& Sons. https://doi. org/10.1002/9781119202097
Rubinstein, M. (1985). Nonparametric Tests of Alternative Option Pricing Models Using All Reported Trades and Quotes on the 30 Most Active CBOE Option Classes from August 23, 1976 through August 31, 1978. The Journal of Finance, 40(2), 455-480. https://doi. org/10.2307/2327895

Rubinstein, M. (1994). Implied Binomial Trees. The Journal of Finance, 49(3), 771-818. https://doi.org/10.2307/2329207

Soini, V., \& Lorentzen, S. (2019). Option prices and implied volatility in the crude oil market. Energy Economics, 83, 515-539. https://doi.org/10.1016/j.eneco.2019.07.011

Tanha, H., \& Dempsey, M. (2015). Do Aussie markets smile? Implied volatility functions and determinants. Applied Economics, 47(30), 3143-3163. https://doi.org/10.1080/00036846. 2015.1013606 